\title{
The role of CDI47 expression in prostate cancer: a systematic review and meta-analysis
}

This article was published in the following Dove Press journal:

Drug Design, Development and Therapy

I August 2016

Number of times this article has been viewed

Yun Ye ${ }^{1,2, *}$

Su-Liang $\mathrm{Li}^{2, *}$

Yao Wang ${ }^{2}$

Yang $\mathrm{YaO}^{2}$

Juan Wang'

Yue-Yun $\mathrm{Ma}^{\prime}$

Xiao-Ke Hao'

'Department of Laboratory Medicine, Xijing Hospital, Fourth Military Medical University, ${ }^{2}$ Department of Clinical Laboratory, The First Affiliated Hospital of Xi'an Medical University,

Xi'an, Shaanxi, People's Republic

of China

*These authors contributed equally to this work
Correspondence: Xiao-Ke Hao

Department of Laboratory Medicine,

Xijing Hospital, Fourth Military Medical

University, I5 Changle West Road,

Xi'an 710032, Shaanxi Province,

People's Republic of China

Tel +86 2984775572

Fax +86298427 7393

Email haoxkg@126.com
Background: There are a number of studies which show that expression of CD147 is increased significantly in prostate cancer ( $\mathrm{PCa}$ ). However, conflicting conclusions have also been reported by other researchers lately. In order to arrive at a clear conclusion, a meta-analysis of eligible studies was conducted.

Materials and methods: We searched PubMed, MEDLINE, Cochrane Library, and the China National Knowledge Infrastructure databases to identify all the published case-control studies on the relationship between the expression of CD147 and PCa until February 2016. In the end, a total of 930 patients in eight studies were included in the meta-analysis.

Results: CD147 expression in the PCa patients increased significantly (odds ratio [OR], 4.65; $95 \%$ confidence interval $[\mathrm{CI}], 3.52-6.14 ; Z=10.79 ; P<0.05)$, but there was obvious heterogeneity between studies ( $P=92.9 \%, P<0.05)$. Subgroup analysis showed that positive expression of CD147 was associated with PCa among the Asian population (OR, 21.01; 95\% CI, 12.88-34.28; $Z=12.19 ; P<0.05)$. Furthermore, it was significantly related to TNM stage (OR, $0.24 ; 95 \% \mathrm{CI}$, $0.17-0.35 ; Z=7.74 ; P<0.05$ ), Gleason score (OR, 0.41; 95\% CI, 0.31-0.56; $Z=5.62 ; P<0.05$ ), differentiation grade (OR, $0.27 ; 95 \% \mathrm{CI}, 0.13-0.56 ; Z=3.47 ; P<0.05)$, and pretreatment serum prostate-specific antigen level (OR, 0.07; 95\% CI, 0.03-0.16; $Z=6.47 ; P<0.05$ ).

Conclusion: Positive expression of CD147 was related to $\mathrm{PCa}$, significant heterogeneity was not found between Asian studies, and the result became more significant. The positive expression of CD147 was significantly related to the clinicopathological characteristics of PCa. This suggests that CD147 plays an essential role in poor prognosis and recurrence prediction.

Keywords: CD147, prostate cancer, meta-analysis

\section{Introduction}

Prostate cancer $(\mathrm{PCa})$ is a common malignant tumor in the urogenital system of men, which seriously threatens men's health and becomes an important cause of death in elderly men, and the mortality rate is the second highest among men worldwide. ${ }^{1,2}$ With the gradual increase of the aging population and the constant increase in the level of clinical diagnosis, morbidity due to PCa has increased greatly. Due to the long duration of its course and the lack of early specific clinical symptoms, the diagnosis, treatment, and prognosis of disease are seriously affected. It is therefore clinically essential to diagnose the condition early, evaluate the degree of malignancy, and improve the prognosis for $\mathrm{PCa}$.

As a member of the immunoglobulin family, extracellular matrix metalloproteinase inducer (EMMPRIN, also known as CD147) is a glycoprotein enriched on the surface of many tumor cells. ${ }^{3,4} \mathrm{CD} 147$ has been demonstrated to participate in different ways in tumor invasion and metastasis by stimulating the synthesis of matrix metalloproteinases (MMPs). ${ }^{5}$ There are some studies regarding the relationship between CD147 and PCa, 
and the results show that positive expression of CD147 is significantly higher in PCa patients compared to controls. ${ }^{6,7}$ As a result, it is reasonable to speculate that expression of CD147 may be closely related to the pathogenesis of PCa. However, inconsistent results have also been reported by other studies. ${ }^{8,9}$ Because such a discrepancy exists among previous studies, a systematic review was conducted to explore the correlation between CD147 expression and PCa, in addition to determining its clinicopathological characteristics.

\section{Materials and methods Search strategy}

This meta-analysis was carried out in accordance with the guidelines of the Meta-analysis of Observational Studies in Epidemiology (MOOSE) group. ${ }^{10}$ We conducted a comprehensive search of PubMed, MEDLINE, Cochrane Library, and the China National Knowledge Infrastructure databases until February 2016. The following search strategy was used: ("CD147" OR "Extracellular matrix metalloproteinase inducer" OR "EMMPRIN") and ("prostate cancer" OR "PCa" OR "prostatic neoplasm" OR "prostate neoplasm" OR "cancer of the prostate" OR "prostatic cancer"). Subsequently, the eligible literature was included for further screening.

\section{Study selection}

Two researchers independently screened the eligible literature. The following criteria for study inclusion were used: it should be a case-control study; the authors had to measure CD147 expression of tumor tissue by immunohistochemical method; and the association between CD147 expression and PCa should be reported. Simultaneously, the exclusion criteria were as follows: animals were used; reviews, comments, and irrelevant articles; and the data comprised continuous variables or were incomplete.

\section{Data extraction}

The following items were collected from the included studies: the first author's name, publication year, country in which the study was performed, study type, study design, sample size, age, ethnicity, detection method for CD147 expression, expression of CD147 in PCa patients with different TNM stages, differentiation grade, and Gleason score.

\section{Study quality}

According to the Newcastle-Ottawa Scale (NOS) for casecontrol studies, ${ }^{11}$ two independent authors (YY and S-LL) evaluated the quality of the included studies. The included studies were respectively classified into two levels: low quality (0-6), and high quality (7-9). ${ }^{12}$ When discrepancies of the enrolled studies existed, a third investigator (YW) was invited to adjudicate.

\section{Statistical analysis}

Heterogeneity was defined as a consequence of methodological and/or statistical diversity among the studies. ${ }^{13}$ Cochran's $Q$-statistic test was used to analyze the heterogeneity ( $P$-values $<0.05$ were treated as statistically significant). ${ }^{14}$ $I^{2}$ test was also used to detect the heterogeneity between studies, the values of which ranged from $0 \%$ (no heterogeneity) to $100 \%$ (maximal heterogeneity). ${ }^{15} I^{2}$ values of $25 \%, 50 \%$, and $75 \%$ represented low, medium, and high heterogeneity. ${ }^{16}$ Sensitivity analysis was conducted to validate the credibility of outcomes through deletion of individual studies in the meta-analysis. Funnel plot was explored to identify whether there was any evidence of publication bias. Symmetry of the funnel plots was further evaluated by Egger's linear regression test. ${ }^{17}$ To calculate the effect size for clinicopathological characteristics, the summary odds ratios (ORs) with their 95\% confidence intervals (CIs) were used for TNM stages I-II versus TNM stages III-IV, high- and mediumdifferentiation grade versus low-differentiation grade, Gleason score $<7$ versus $\geq 7$, and low prostate-specific antigen (PSA) level ( $<10 \mathrm{ng} / \mathrm{mL})$ versus high PSA level ( $\geq 10 \mathrm{ng} /$ $\mathrm{mL}$ ) categories of CD147 expression. We conducted a subgroup meta-analysis to explore the potential effect of ethnicity. Statistical analyses were carried out using the statistical software Stata version 12.0 (StataCorp LP, College Station, TX, USA) with a two-sided test. All tests were two sided, and a $P$-value of 0.05 was regarded as statistically significant.

\section{Results}

\section{Literature search}

The details of the study search are presented in a flow diagram (Figure 1). In total, 115 relevant studies were identified. After carefully reading the articles, we excluded 47 studies because they were duplicates, letters, reviews, nonhuman studies, or contained limited data. Following the reading of the remaining studies, additional studies were excluded because they were not case-control studies and because they were not relevant to CD147 or PCa. Finally, eight case-control studies were included in the meta-analysis. The selection process is shown in Figure 1.

\section{Study characteristics}

The characteristics of the selected studies are listed in Table 1. Eight studies were published between 2008 and 2015: six studies from Asia, ${ }^{18-23}$ one from Australia, ${ }^{24}$ and 


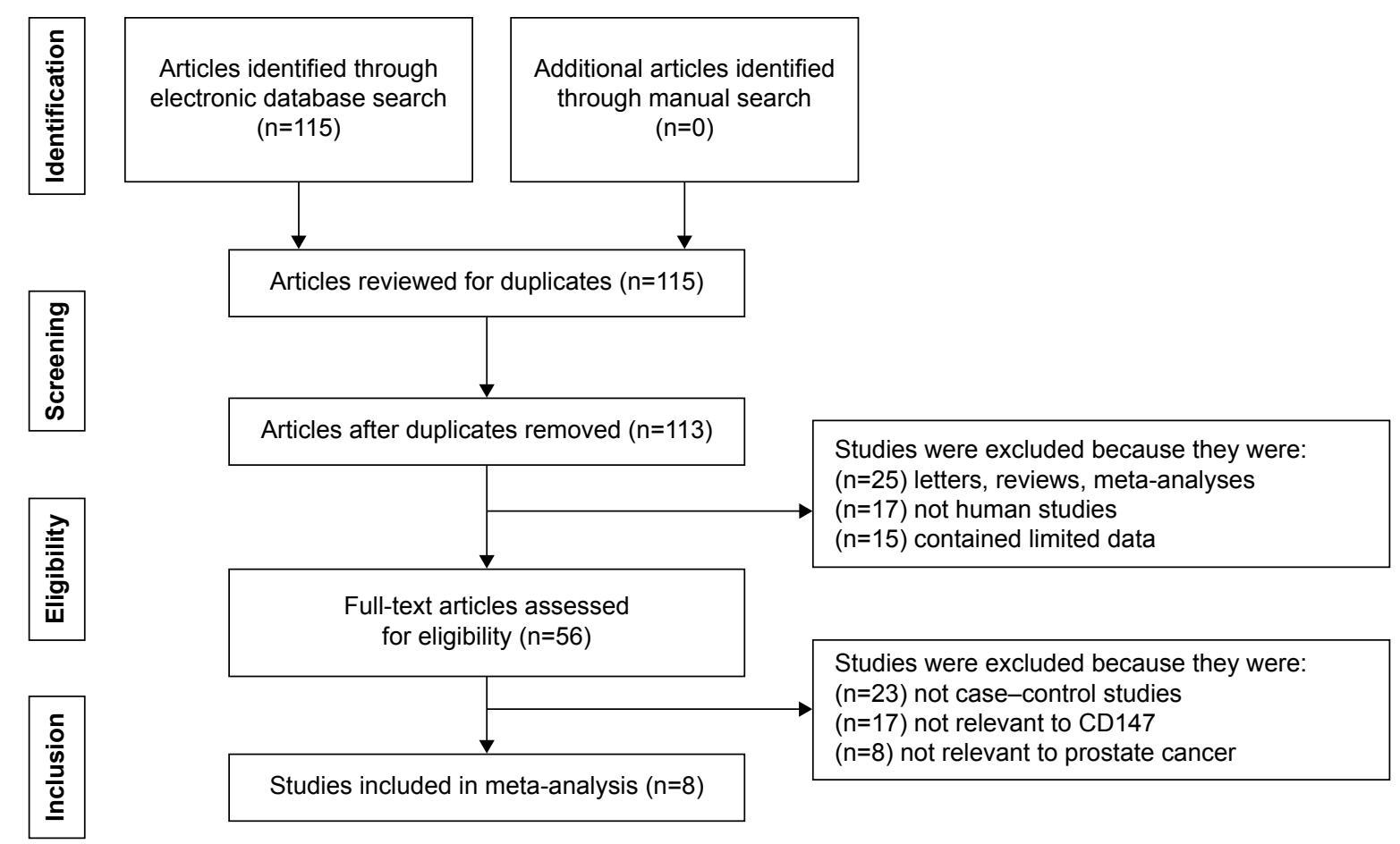

Figure I Flowchart showing study-selection procedure.

one from Europe. ${ }^{25}$ Furthermore, we compared the rate of positive expression of $\mathrm{CD} 147$ between the following pairs: Gleason score $<7$ and Gleason score $\geq 7$ groups (seven studies); TNM I+II and TNM III+IV groups (seven studies); high- and medium-differentiation and the low-differentiation groups (three studies), and low and high PSA level groups (two studies). The median NOS score of seven was identified as a reliable quality.

\section{Meta-analysis}

Correlation between CDI47 expression and PCa

We compared the rate of positive expression of CD147 in the eight included studies. The pooled OR was 4.65 (95\% CI, $3.52-6.14 ; Z=10.79 ; P<0.05)$ and there was evidence of heterogeneity between studies $\left(I^{2}=92.9 \%, P<0.05\right)$ (Figure 2).

\section{Subgroup analysis}

We used subgroup analyses to explore heterogeneity. Subgroup analysis based on ethnicity implied that positive expression of CD147 was related to $\mathrm{PCa}$ in the Asian population (OR, 21.01; 95\% CI, 12.88-34.28; $Z=12.19 ; P<0.05$ ) (Figure 3).

\section{Association between positive expression of CDI47 and clinicopathological characteristics of $\mathrm{PCa}$}

We compared the rate of positive expression of CD147 between the TNM I+II and TNM III+IV stages in seven

Table I Characteristics of the eligible studies included in the meta-analysis

\begin{tabular}{|c|c|c|c|c|c|c|c|c|c|}
\hline \multirow[t]{2}{*}{ Study } & \multirow{2}{*}{$\begin{array}{l}\text { Study } \\
\text { location }\end{array}$} & \multicolumn{2}{|c|}{ Sample size, $n$} & \multicolumn{2}{|c|}{ Age, years $^{a}$} & \multicolumn{2}{|c|}{ CDI47 positive, $\%$} & \multirow[t]{2}{*}{ Measurement } & \multirow[t]{2}{*}{ NOS score } \\
\hline & & Case & Control & Case & Control & Case & Control & & \\
\hline Cai et $\mathrm{al}^{23}$ & Asia & 56 & 22 & $53-80$ & $59-89$ & 64.3 & 9.1 & $\mathrm{IHC}$ & 6 \\
\hline Feng and Feng ${ }^{22}$ & Asia & 60 & 15 & $59-89$ & $59-80$ & 61.7 & 26.7 & $\mathrm{IHC}$ & 7 \\
\hline Han et $a^{18}$ & Asia & 62 & 30 & $58-86$ & NR & 82.3 & 13.3 & $\mathrm{IHC}$ & 7 \\
\hline He et al $^{19}$ & Asia & 101 & 90 & 73.5 & NR & 66.3 & 23.3 & $\mathrm{IHC}$ & 7 \\
\hline Wang et $\mathrm{al}^{21}$ & Asia & 54 & 40 & $33-77$ & $35-79$ & 84.4 & 17.5 & $\mathrm{IHC}$ & 6 \\
\hline $\mathrm{Bi}$ et $\mathrm{al}^{20}$ & Asia & 300 & 20 & $45-86$ & $46-72$ & 62.0 & 5.0 & $\mathrm{IHC}$ & 7 \\
\hline Madigan et $\mathrm{al}^{24}$ & Australia & 120 & 15 & $46-72$ & $53-72$ & 65.0 & 13.3 & $\mathrm{IHC}$ & 8 \\
\hline Pértega-Gomes et $\mathrm{al}^{25}$ & Europe & 167 & 134 & $46-74$ & NR & 49.7 & 40.8 & $\mathrm{IHC}$ & 8 \\
\hline
\end{tabular}

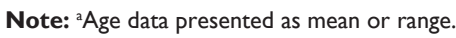

Abbreviations: IHC, immunohistochemistry; NOS, Newcastle-Ottawa Scale; NR, not reported. 


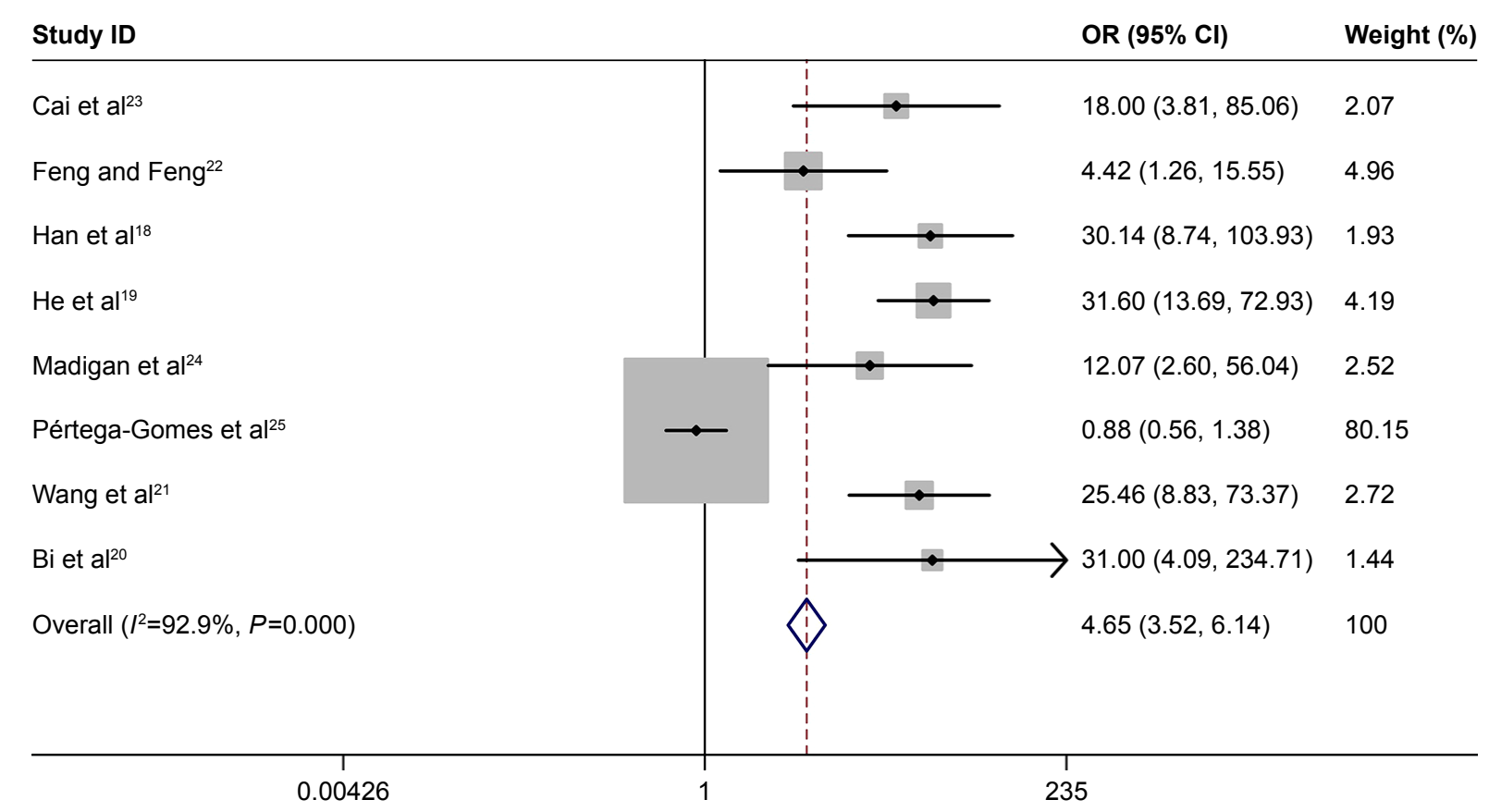

Figure 2 Forest plots for the relationship between CDI47 expression and prostate cancer.

Note: The data are for case versus control.

Abbreviations: $\mathrm{Cl}$, confidence interval; OR, odds ratio.

Study ID

Asian

Cai et $\mathrm{a}^{23}$

Feng and Feng ${ }^{22}$

Han et al ${ }^{18}$

He et al $^{19}$

Wang et $\mathrm{al}^{21}$

Bi et $a^{20}$

Subtotal $\left(I^{2}=32.9 \%, P=0.190\right)$

\section{Australia}

Madigan et $\mathrm{al}^{24}$

Europe

Pértega-Gomes et al ${ }^{25}$

Overall $\left(I^{2}=92.9 \%, P=0.000\right)$
OR $(95 \% \mathrm{CI})$

Weight (\%)

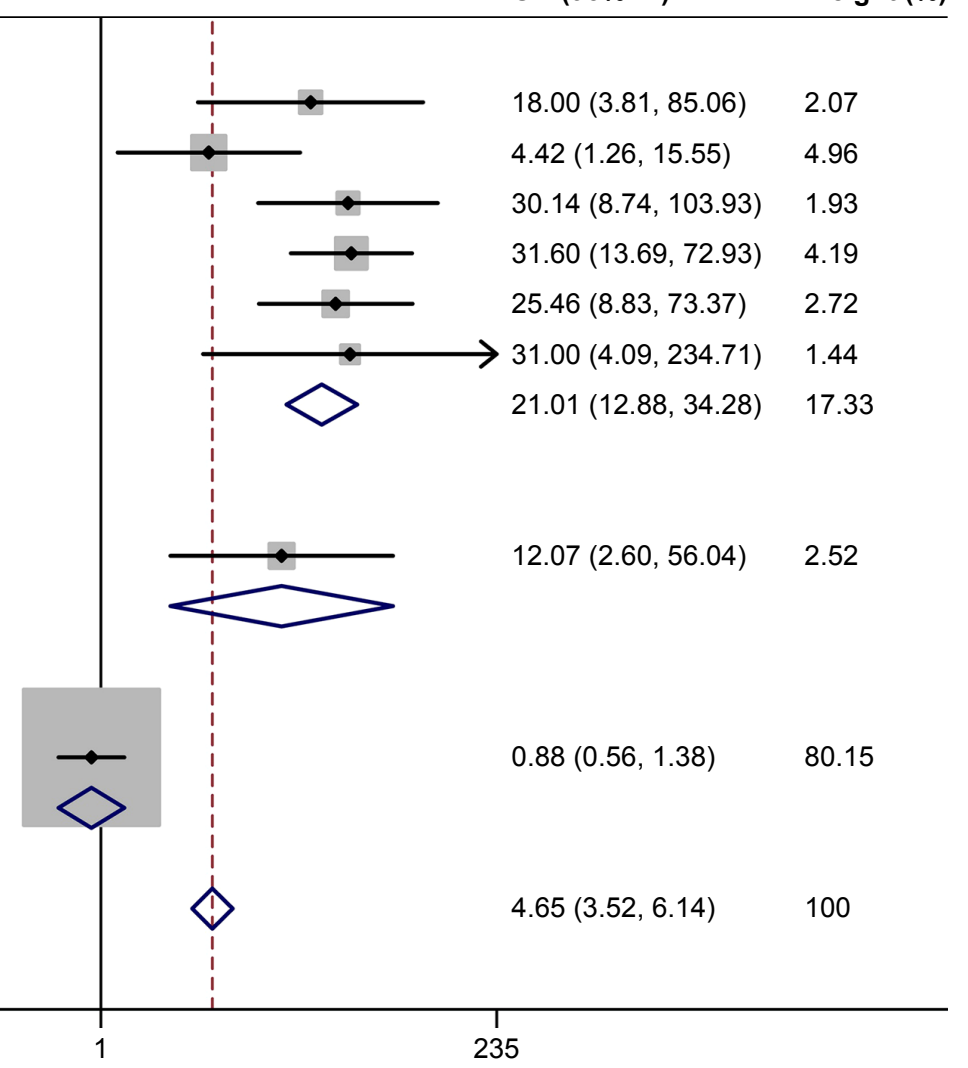

Figure 3 Subgroup analysis of the relationship between CDI47 expression and prostate cancer.

Note: The data are for case versus control.

Abbreviations: $\mathrm{Cl}$, confidence interval; OR, odds ratio. 


\begin{tabular}{|c|c|c|}
\hline Study ID & OR $(95 \% \mathrm{Cl})$ & Weight (\%) \\
\hline \multicolumn{3}{|l|}{ TNM } \\
\hline Cai et $\mathrm{al}^{23}$ & $0.21(0.07,0.70)$ & 3.45 \\
\hline Han et $\mathrm{al}^{18}$ & $0.14(0.02,1.18)$ & 2.01 \\
\hline He et al ${ }^{19}$ & $0.20(0.08,0.49)$ & 5.93 \\
\hline Madigan et $\mathrm{al}^{24}$ & $0.37(0.12,1.16)$ & 3.02 \\
\hline Pértega-Gomes et $\mathrm{al}^{25}$ & $0.14(0.05,0.35)$ & 8.01 \\
\hline Wang et $\mathrm{al}^{21}$ & $0.26(0.09,0.76)$ & 3.65 \\
\hline $\mathrm{Bi}$ et $\mathrm{al}^{20}$ & $0.32(0.18,0.58)$ & 12.28 \\
\hline Subtotal $\left(I^{2}=0.0 \%, P=0.786\right)$ & $0.24(0.17,0.35)$ & 38.35 \\
\hline \multirow{2}{*}{\multicolumn{3}{|c|}{ Gleason score }} \\
\hline & & \\
\hline Cai et $\mathrm{al}^{23}$ & $0.12(0.01,1.01)$ & 2.15 \\
\hline Feng and Feng 22 & $0.25(0.08,0.84)$ & 2.97 \\
\hline Han et $\mathrm{al}^{18}$ & $0.75(0.20,2.90)$ & 1.43 \\
\hline He et $\mathrm{al}^{19}$ & $1.16(0.51,2.65)$ & 3.00 \\
\hline Madigan et $\mathrm{al}^{24}$ & $0.28(0.10,0.82)$ & 3.43 \\
\hline Pértega-Gomes et $\mathrm{al}^{25}$ & $0.46(0.24,0.89)$ & 7.61 \\
\hline $\mathrm{Bi}$ et $\mathrm{al}^{20}$ & $0.32(0.20,0.53)$ & 16.07 \\
\hline Subtotal $\left(I^{2}=41.9 \%, P=0.112\right)$ & $0.41(0.31,0.56)$ & 36.66 \\
\hline \multicolumn{3}{|l|}{ Differentiation grade } \\
\hline Han et $\mathrm{al}^{18}$ & $0.05(0.00,0.83)$ & 2.37 \\
\hline He et $a^{19}$ & $0.34(0.14,0.84)$ & 4.81 \\
\hline Wang et $\mathrm{al}^{21}$ & $0.39(0.08,2.03)$ & 1.51 \\
\hline Subtotal $\left(I^{2}=0.0 \%, P=0.387\right)$ & $0.27(0.13,0.56)$ & 8.69 \\
\hline \multicolumn{3}{|l|}{ PSA } \\
\hline Pértega-Gomes et $\mathrm{al}^{25}$ & $0.07(0.03,0.18)$ & 11.74 \\
\hline Madigan et $\mathrm{al}^{24}$ & $0.07(0.02,0.35)$ & 4.56 \\
\hline Subtotal $\left(I^{2}=0.0 \%, P=0.944\right)$ & $0.07(0.03,0.16)$ & 16.30 \\
\hline 0.0024 & $\begin{array}{c}1 \\
402\end{array}$ & \\
\hline
\end{tabular}

Figure 4 Forest plots for the relationship between CDI47 expression and clinicopathological characteristics of prostate cancer. Abbreviations: $\mathrm{Cl}$, confidence interval; OR, odds ratio; PSA, prostate-specific antigen; TNM, tumor-node-metastasis.

studies. The pooled OR was 0.24 (95\% CI, 0.17-0.35; $Z=7.74$; $P<0.05)$, with no significant heterogeneity $\left(I^{2}=0 \%, P=0.79\right)$. In addition, the rate of positive expression of CD147 between the groups with Gleason scores $<7$ and $\geq 7$ was compared in seven studies. The pooled OR was 0.41 (95\% CI, 0.31-0.56; $Z=5.62 ; P<0.05)$, with no significant heterogeneity $\left(I^{2}=42 \%\right.$, $P=0.11)$. Furthermore, CD147 was more highly expressed in PCa patients with high differentiation grade in three studies (OR, 0.27; 95\% CI, 0.13-0.56; $Z=3.47 ; P<0.05$ ), and no evidence of heterogeneity was detected $\left(I^{2}=0 \%, P=0.39\right)$. The results also suggest that CD147 was more highly expressed in PCa patients with high PSA level in two studies (OR, 0.07; 95\% CI, 0.03-0.16; $Z=6.47 ; P<0.05)$, with no evidence of heterogeneity $\left(I^{2}=0 \%, P=0.95\right)$ (Figure 4$)$. Therefore, the positive expression of CD147 was associated with the clinicopathological characteristics of PCa patients.

\section{Publication bias and sensitivity analysis}

The overall statistical significance did not change when any single study was omitted. Sensitivity analysis shows that data are relatively stable and credible (Figure 5). The funnel plots of the studies were symmetrical, and Egger's test showed no publication bias (Figure 6). As the number of included studies that investigated the relation between PSA level and CD147 expression was $<3$, we did not carry out publication bias and sensitivity analyses.

\section{Discussion}

$\mathrm{PCa}$ is the most common malignant tumor of the male reproductive system and its incidence is ranked the second in the world. A projected 180,890 new cases of PCa will be diagnosed and an estimated 26,120 men may die of the disease in the USA alone in 2016. The mortality due to PCa accounts for $8 \%$ of all cancer deaths. ${ }^{26}$ The incidence of this disease has obvious heterogeneous geographical and ethnic characteristics, and prognosis presents a different scenario according to the operation method, pathological type, tumor stage, and other factors. ${ }^{27}$ For these reasons, we need precise biological indicators to guide treatment and monitor the progress of disease in $\mathrm{PCa}$ patients.

Positive expression of CD147 was found in many cancer tissues, which is related to poor prognosis for the patient. ${ }^{28-31}$ 


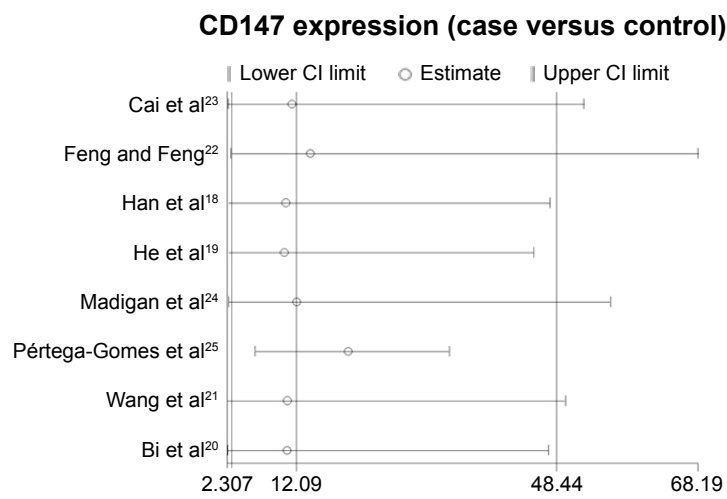

Gleason score ( $<7$ versus $\geq 7$ )

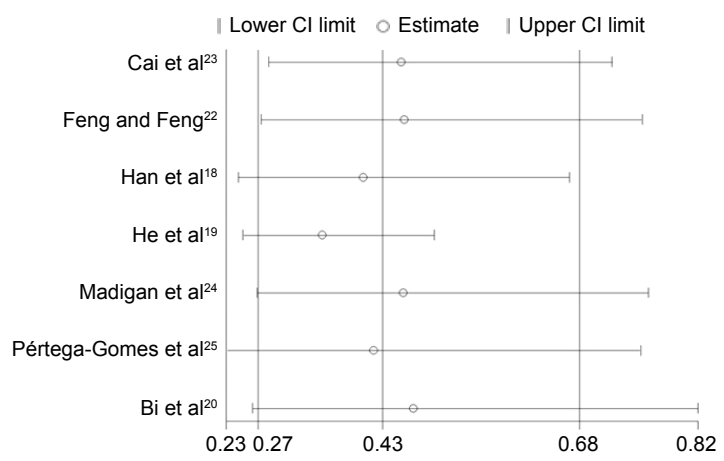

TNM stage (I-II versus III-IV)

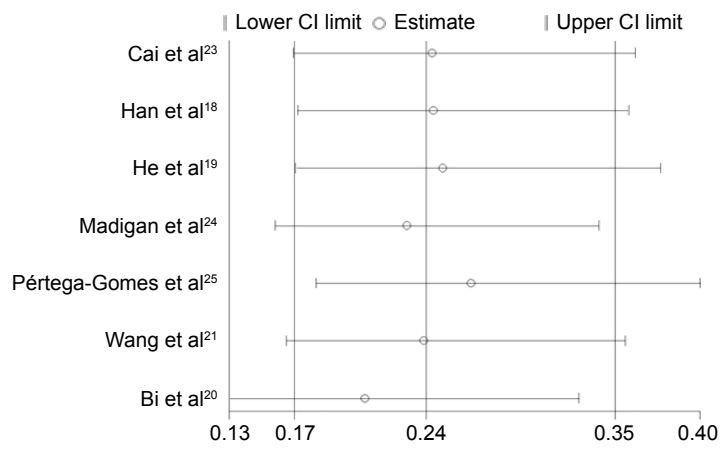

Differentiation grade

(high and medium versus low)

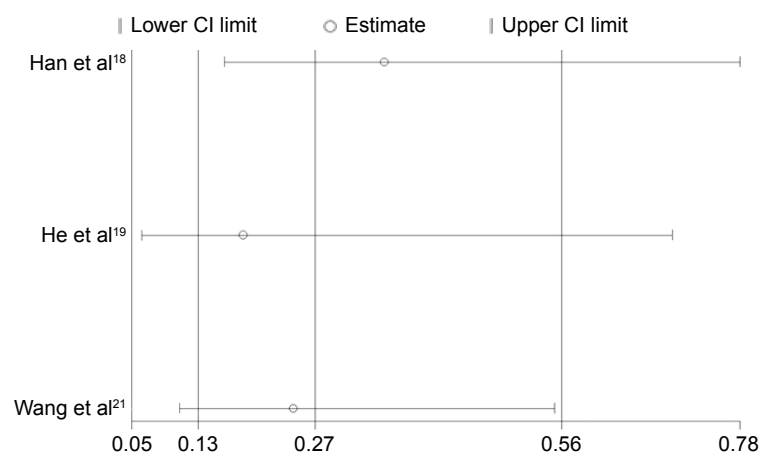

Figure $\mathbf{5}$ Sensitivity analyses of the summary odds ratio coefficients.

Abbreviations: $\mathrm{Cl}$, confidence interval; OR, odds ratio; TNM, tumor-node-metastasis.
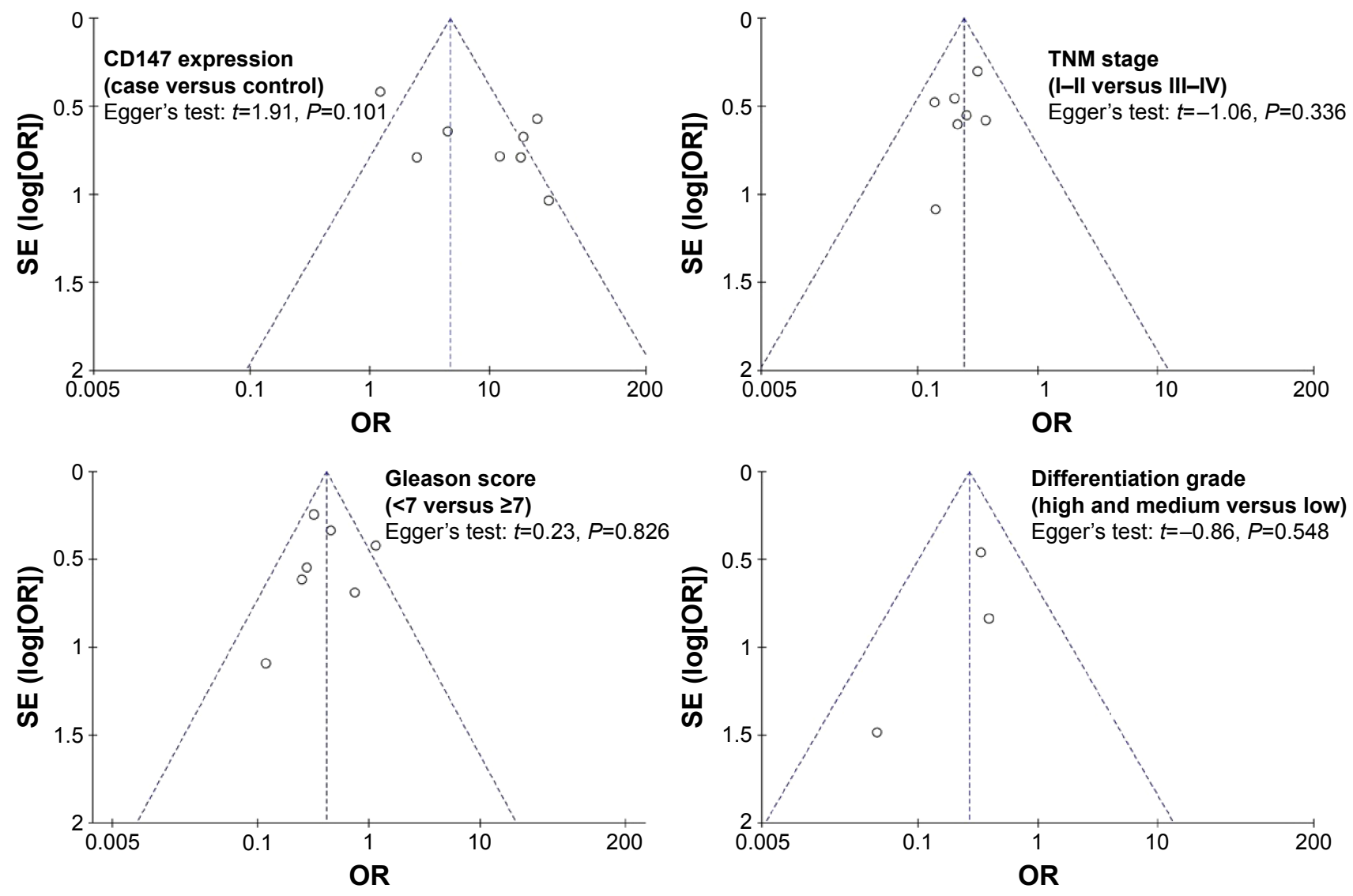

Figure 6 Funnel plots of publication biases.

Abbreviations: $\mathrm{Cl}$, confidence interval; OR, odds ratio; SE, standard error; TNM, tumor-node-metastasis. 
Some studies showed that CD147 plays an essential part in the progression and metastasis of $\mathrm{PCa}{ }^{7,32}$ However, other relevant studies have reported contradictory findings. ${ }^{8,9}$ Additionally, there is no relevant meta-analysis that reports the relationship between CD147 expression and PCa so far. Therefore, we conducted the present meta-analysis to explore the relationship between expression of CD147 and PCa.

We included 930 cases and 366 controls of eight studies in this meta-analysis. The pooled OR was $4.65(95 \%$ CI, 3.52-6.14; $Z=10.79 ; P<0.05)$, indicating that CD147 expression was associated with $\mathrm{PCa}$. However, there was obvious heterogeneity between the studies $\left(I^{2}=92.9 \%\right.$, $P<0.05)$. Additionally, subgroup analysis based on ethnicity suggests that positive expression of CD147 was associated with $\mathrm{PCa}$ in the Asian population (OR, 21.01; 95\% CI, 12.88-34.28; $Z=12.19 ; P<0.05)$. There was no obvious heterogeneity between the studies conducted in Asian populations, and the result became more significant $\left(I^{2}=33 \%, P=0.19\right)$. This indicates that the heterogeneity is derived from ethnicity.

Pretreatment clinical TNM staging, Gleason score, differentiation grade, and serum PSA level are clinicopathological characteristics of $\mathrm{PCa}$, which can indicate the prognosis of patients and have an important clinical value in determining PCa. We calculated the effect size for clinicopathological characteristics. There was no significant heterogeneity and we found that the association between clinicopathological characteristics of $\mathrm{PCa}$ and positive expression of CD147 is significant. It suggests that CD147 plays an important role in poor prognosis and prediction of $\mathrm{PCa}$ recurrence.

Riethdorf et $\mathrm{al}^{33}$ analyzed the incidence of CD147 expression in different tumor types and found a remarkable difference in CD147 expression levels. Another investigation of expression and function of CD147 as a cancer-associated biomarker showed the following incidence rates of CD147 expression in various cancers: cancers of the liver $(80 \%)$, prostate $(80 \%)$, lung $(62 \%)$, stomach $(66 \%)$, colon $(58 \%)$, rectum $(59 \%)$, breast $(64 \%)$, brain $(90 \%)$, esophagus $(87 \%)$, ovary $(75 \%)$, urinary bladder (85\%), and skin (58\%). ${ }^{34}$ These results can render CD147 as the therapeutic target in a broad range of cancer types and could be used for differential diagnosis.

Based on the current results of meta-analysis, we assume that the expression of CD147 is a clinical biomarker for PCa, which could affect the clinicopathological characteristics of PCa. Nevertheless, certain limitations of our study should be considered. First, continuous variable data were not included in this study. Second, the included studies were limited to those written in Chinese or English. Third, the majority of the included studies were conducted in the Asian population.

\section{Conclusion}

Positive CD147 expression may be related to PCa and deterioration in terms of the clinicopathological characteristics of PCa. CD147 could serve as a biomarker for the diagnosis and prognosis of PCa patients. We should conduct further investigations to evaluate the role of CD147 expression in PCa.

\section{Acknowledgments}

This study was supported by the Education Department of Shaanxi Provincial Government (11JK0723) and the First Affiliated Hospital of Xi'an Medical University (XYFY14-02). The authors express their gratitude to the study participants and research personnel for their involvement in the study. They would also like to thank Professor Ming Xie and Professor Yuqiang Ji for their valuable assistance.

\section{Disclosure}

The authors report no conflicts of interest in this work.

\section{References}

1. Ferlay J, Shin HR, Bray F, Forman D, Mathers C, Parkin DM Estimates of worldwide burden of cancer in 2008: GLOBOCAN 2008. Int J Cancer. 2010;127(12):2893-2917.

2. Siegel RL, Miller KD, Jemal A. Cancer statistics, 2015. CA Cancer J Clin. 2015;65:5-29.

3. Zeng HZ, Qu YQ, Liang AB, et al. Expression of CD147 in advanced non-small cell lung cancer correlated with cisplatin-based chemotherapy resistance. Neoplasma. 2011;58(5):449-454.

4. Nagashima S, Sakurai K, Suzuki S, et al. CD147 expression in noninvasive and invasive breast carcinoma. Gan To Kagaku Ryoho. 2014; 41:1267-1269.

5. Grass GD, Toole BP. How, with whom and when: an overview of CD147-mediated regulatory networks influencing matrix metalloproteinase activity. Biosci Rep. 2015;36(1):e00283.

6. Zhu H, Zhao J, Zhu B, et al. EMMPRIN regulates cytoskeleton reorganization and cell adhesion in prostate cancer. Prostate. 2012;72(1):72-81.

7. Bilgin Doğru E, Dizdar Y, Akşit E, Ural F, Şanlı Ö, Yasasever V. EMMPRIN and ADAM12 in prostate cancer: preliminary results of a prospective study. Tumour Biol. 2014;35(11):11647-11653.

8. Bauman TM, Ewald JA, Huang W, Ricke WA. CD147 expression predicts biochemical recurrence after prostatectomy independent of histologic and pathologic features. BMC Cancer. 2015;15:549.

9. Grupp K, Hohne TS, Prien K, et al. Reduced CD147 expression is linked to ERG fusion-positive prostate cancers but lacks substantial impact on PSA recurrence in patients treated by radical prostatectomy. Exp Mol Pathol. 2013;95(2):227-234.

10. Stroup DF, Berlin JA, Morton SC, et al. Meta-analysis of observational studies in epidemiology: a proposal for reporting. Meta-analysis of observational studies in epidemiology (MOOSE) group. JAMA. 2000; 283:2008-2012.

11. Stang A. Critical evaluation of the Newcastle-Ottawa scale for the assessment of the quality of nonrandomized studies in meta-analyses. Eur J Epidemiol. 2010;25:603-605.

12. Zhang P, Zhong ZH, Yu HT, Liu B. Significance of increased leptin expression in osteoarthritis patients. PLoS One. 2015;10(4):e0123224.

13. Higgins JPT, Green S, editors. Cochrane Handbook for Systematic Reviews of Interventions 4.2.6 [updated September 2006]. Available from: http://www.cochrane.org/resources/handbook/hbook.htm. Accessed April 26, 2016. 
14. Jackson D, White IR, Riley RD. Quantifying the impact of betweenstudy heterogeneity in multivariate meta-analyses. Stat Med. 2012; 31(29):3805-3820.

15. Peters JL, Sutton AJ, Jones DR, Abrams KR, Rushton L. Comparison of two methods to detect publication bias in meta-analysis. JAMA. 2006;295:676-680.

16. Higgins JP, Thompson SG, Deeks JJ, Altman DG. Measuring inconsistency in meta-analyses. BMJ. 2003;327:557-560.

17. Zintzaras E, Ioannidis JP. HEGESMA: genome search meta-analysis and heterogeneity testing. Bioinformatics. 2005;21(18):3672-3673.

18. Han ZD, Bi XC, Qin WJ, et al. CD147 expression indicates unfavourable prognosis in prostate cancer. Pathol Oncol Res. 2009;15(3):369-374.

19. He HC, Han ZD, Dai QS, et al. Expression and significance of CD147 protein inprostate cancer. Zhonghua Yi Xue Za Zhi. 2009;89:1844-1846.

20. Bi XC, Liu JM, Zheng XG, et al. Over-expression of extracellular matrix metalloproteinase inducer in prostate cancer is associated with high risk of prostate-specific antigen relapse after radical prostatectomy. Clin Invest Med. 2011;34(6):E358.

21. Wang Q, Zhang JG, Wang W. Expression and significance of S100P, CD147, and OCT4 in different prostate cancer tissue TNM stages. Genet Mol Res. 2015;14:6844-6851.

22. Feng ME, Feng L. To investigate the expression of the STAT3 and CD147 in human prostate cancer. J Nanchang Univ. 2010;50:12-15.

23. Cai CY, Wu CY, Yang YF, Li SR, Shi XM. Expression and clinical significance of CD147 protein in human prostate cancer. J Clin Res. 2015;32:2088-2090.

24. Madigan MC, Kingsley EA, Cozzi PJ, Delprado WJ, Russell PJ, Li Y. The role of extracellular matrix metalloproteinase inducer protein in prostate cancer progression. Cancer Immunol Immunother. 2008; 57(9):1367-1379.
25. Pértega-Gomes N, Vizcaíno JR, Miranda-Gonçalves V, et al. Monocarboxylate transporter 4 (MCT4) and CD147 overexpression is associated with poor prognosis in prostate cancer. BMC Cancer. 2011;11:312.

26. Siegel RL, Miller KD, Jemal A. Cancer statistics, 2016. CA Cancer J Clin. 2016;66:7-30.

27. Boyd LK, Mao X, Lu YJ. The complexity of prostate cancer: genomic alterations and heterogeneity. Nat Rev Urol. 2012;9(11):652-664.

28. Monteiro LS, Delgado ML, Ricardo S, et al. EMMPRIN expression in oral squamous cell carcinomas: correlation with tumor proliferation and patient survival. Biomed Res Int. 2014;2014:905680.

29. Kong LM, Liao CG, Zhang Y, et al. A regulatory loop involving miR-22, Sp1, and c-Myc modulates CD147 expression in breast cancer invasion and metastasis. Cancer Re. 2014;74(14):3764-3778.

30. Afonso J, Longatto-Filho A, Baltazar F, et al. CD147 overexpression allows an accurate discrimination of bladder cancer patients' prognosis. Eur J Surg Oncol. 2011;37(9):811-817.

31. Xue YJ, Lu Q, Sun ZX. CD147 overexpression is a prognostic factor and a potential therapeutic target in bladder cancer. Med Oncol. 2011;28(4):1363-1372.

32. Zhong WD, Liang YX, Lin SX, et al. Expression of CD147 is associated with prostate cancer progression. Int J Cancer. 2012;130:300-308.

33. Riethdorf S, Reimers N, Assmann V, et al. High incidence of EMMPRIN expression in human tumors. Int J Cancer. 2006;119:1800-1810.

34. Li Y, Xu J, Chen L, et al. HAb18G (CD147), a cancer-associated biomarker and its role in cancer detection. Histopathology. 2009;54(6): $677-687$.
Drug Design, Development and Therapy

\section{Publish your work in this journal}

Drug Design, Development and Therapy is an international, peerreviewed open-access journal that spans the spectrum of drug design and development through to clinical applications. Clinical outcomes, patient safety, and programs for the development and effective, safe, and sustained use of medicines are a feature of the journal, which

\section{Dovepress}

has also been accepted for indexing on PubMed Central. The manuscript management system is completely online and includes a very quick and fair peer-review system, which is all easy to use. Visit http://www.dovepress.com/testimonials.php to read real quotes from published authors. 